\title{
Genetic evidence for occurrence of Macrovipera razii (Squamata, Viperidae) in the central Zagros region, Iran
}

\author{
Hamzeh Oraie ${ }^{1,2}$ \\ 1 Department of Zoology, Faculty of Science, Shahrekord University, Shahrekord, Iran \\ 2 Department of Biodiversity, Institute of Biotechnology, Shahrekord University, Shahrekord, Iran \\ http://zoobank.org/955A477F-7833-4D2A-8089-E4B4D48B0E31 \\ Corresponding author: Hamzeh Oraie (stenodactylus@gmail.com)
}

Academic editor: Peter Mikulíček • Received 16 February 2020 • Accepted 17 March 2020 • Published 9 April 2020

\begin{abstract}
This study presents the first molecular evidence of Macrovipera razii from central Zagros, more than $300 \mathrm{~km}$ north-west of its prior records in southern Iran. Molecular analyses based on mitochondrial cytochrome b sequences identified the individuals from central Zagros as a lineage of M. razii. Specimens from the new localities are separated by a genetic distance of $1.46 \%$ from the known populations of $M$. razii. The results extend the known distribution range of $M$. razii as an endemic species of Iran.
\end{abstract}

\section{Key Words}

Iran, Macrovipera, mtDNA, new record, Razi’s Viper, taxonomy, Viperidae

Central Zagros is a mainly mountainous region in the Chaharmahal and Bakhtiari Province and surrounding areas of Iran. Its climatic conditions and topographic intricacy contribute to unique ecological conditions and a significant level of biodiversity. Several endemic species of the Iranian herpetofauna are restricted to this region (e.g. Iranolacerta zagrosica and Montivipera kuhrangica) (Safaei-Mahroo et al. 2015). However, this area has received less attention, at least for the blunt-nosed vipers of the genus Macrovipera.

The venomous snakes of the genus Macrovipera Reuss, 1927 are distributed over a wide range embracing central Asia, the Middle East and northern Africa (McDiarmid et al. 1999; Khan 2004; Lenk et al. 2001; Stümpel and Joger 2009). Two out of three Macrovipera taxa are reported from Iran (Uetz and Hošek 2019). The first of these is Macrovipera lebetina (Linnaeus, 1758) with two representatives, Macrovipera lebetina obtusa (Dwigubsky 1832) in western and northwestern Iran, and Macrovipera lebetina cernovi (Chikin and Szczerbak 1992) in northeastern parts. The other is one of the most recently described species of Iranian herpetofauna,
Macrovipera razii, described by Oraie et al. (2018) based on a holotype collected at $105 \mathrm{~km}$ on the road from Jiroft to Bam near Bab-Gorgi village and Valley, Kerman Province. The known distribution range of $M$. razii is reported as the central and southern parts of Iran (Oraie et al. 2018). Since Macrovipera specimens from the central Zagros region have never been subject to molecular analysis, the corresponding genetic data of specimens from four distinct localities in Chaharmahal and Bakhtiari Province are presented here (Fig. 1A).

Four tissue samples from dead individuals (road traffic casualties or killed by rural people) have been obtained during my surveys in the Chaharmahal and Bakhtiari Province between 2018 and 2019. Specimens were found in foothills of the Zagros mountains at altitudes between 1800 and $2900 \mathrm{~m}$ a. s. 1. Names of the localities and their coordinates are in the legend of the Fig. 1.

The tissue samples were preserved in $96 \%$ ethanol and kept at $-20^{\circ}$ in the Shahrekord University Herpetological Collection (HAC), Iran. DNA was extracted using Aron-Gene Kit (Aron-Gene, Isfahan, Iran) following the instructions provided by the manufacturer. A fragment of 


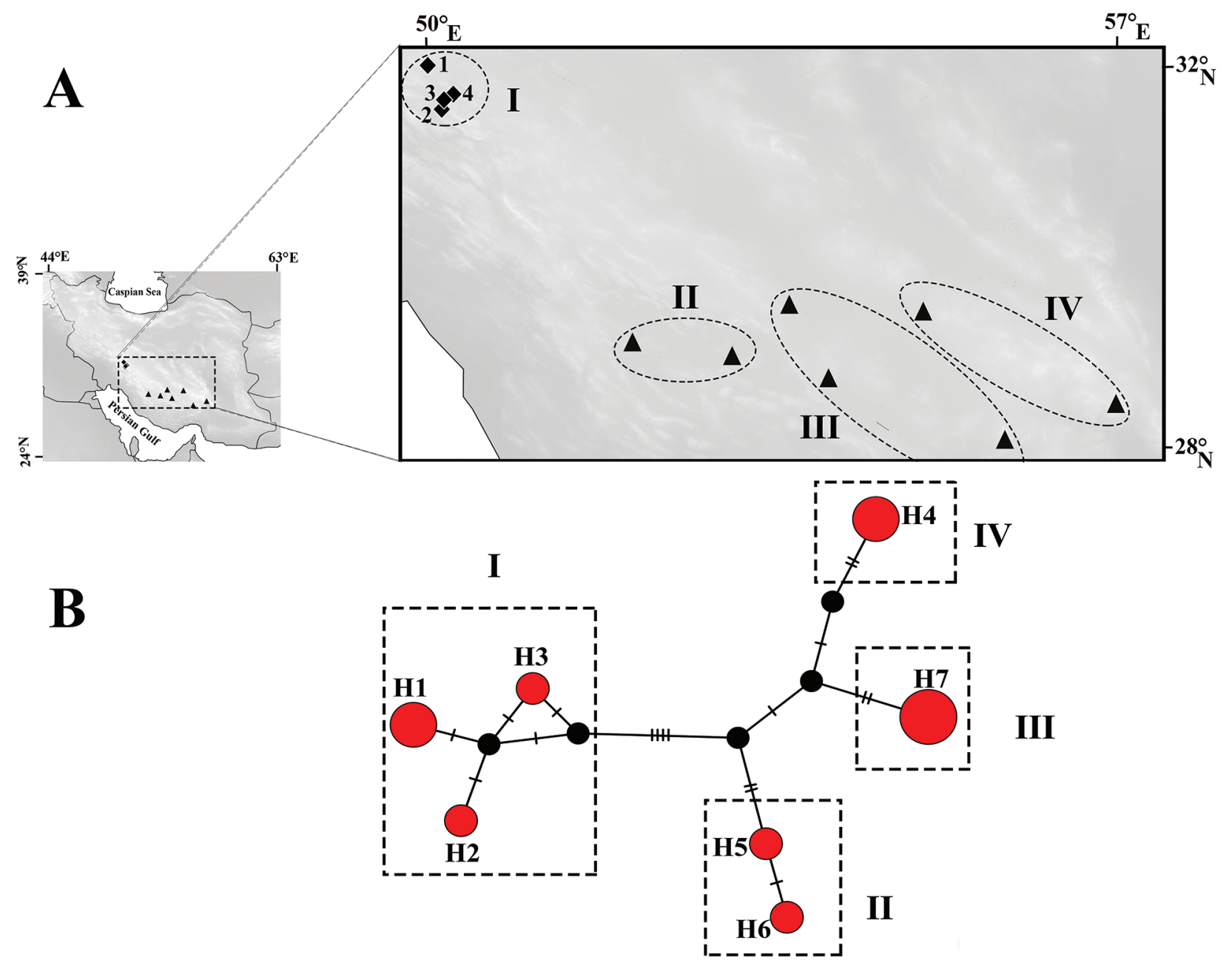

Figure 1. A) Distribution of Macrovipera razii in Iran. Black lozenges (group I) represent the localities of the specimens in the present study, black triangles represent records used in Oraie et al. )2018(. I: Central Zagros region, 1: Around Harooni, North-West of Shahrekord (32.378807 N, 50.544209 E), 2: South Ardal (31.950942 N, 50.6871043 E), 3: Around Shalamzar (32.043408 N, 50.709343 E), 4: Around Mosa-Abad, South of Shahrekord (32.098472 N, 50.805111 E); II: Foothills of Fars Province; III: Central Iranian plateau; IV: High Altitude of Kerman Province. B) A median-joining network connecting 7 haplotypes found in the Cytb sequence data set. Median vector shown with black nodes, the branch length is indicated through the numbers of mutational steps joining the haplotypes. Central Zagros region (H1: HAC 805, HAC 777, H2: HAC 529, H3: HAC 670); High Altitude of Kerman Province (H4: ERP 143, ERP 1941); Foothills of Fars Province (H5: ERP 1518, H6: ERP 1981); Central Iranian plateau (H7: ERP 3183, ERP 2376, ERP 1531).

the mitochondrial Cytochrome $b$ (Cytb) gene was amplified (PCR) using the primers F1_Cytb (5'-TGAGGCCTGAAAAACCACCGTTG-3') (Stümpel 2012) and Ei700r (5'-GGGGTGAAAGGGGATTTTRTC-3') (Rastegar-Pouyani et al. 2010), following PCR conditions described in Oraie et al. (2018).

Four DNA sequences generated by this study were submitted to GenBank (HAC_529: MN991204; HAC_670: MN991203; HAC_777: MN991202; HAC_805: MN991201). Published Cytb sequences of Macrovipera (Oraie et al. 2018) were retrieved from NCBI (http:// www.ncbi.nlm.nih.gov). The sequences were trimmed and aligned using BioEdit 7.1.3 (Hall 1999). A dataset with the final sequence length of 604 nucleotides (113 nt variable; 89 nt parsimony informative; $490 \mathrm{nt}$ conserved) was generated. The mean genetic distances were estimated using Mega X (Kumar et al. 2018). The data set was partitioned by codon positions and the model-finder implemented in IQ-TREE (Nguyen et al. 2015) was used to find the best-fit model of evolution for each partition based on the Bayesian Information Criterion (BIC) (Kalyaanamoorthy et al. 2017). The maximum likelihood (ML) analysis was performed using IQ-TREE (Nguyen et al. 2015), with TIM2e $+\mathrm{I}\left(1^{\text {st }}\right), \mathrm{HKY}+\mathrm{F}+\mathrm{I}\left(2^{\text {nd }}\right)$ and $\mathrm{TN}+\mathrm{F}+\mathrm{I}\left(3^{\text {rd }}\right)$; as the best-fit model of evolution for each partition. The analysis was performed with 1000 bootstrap pseudoreplicates using 


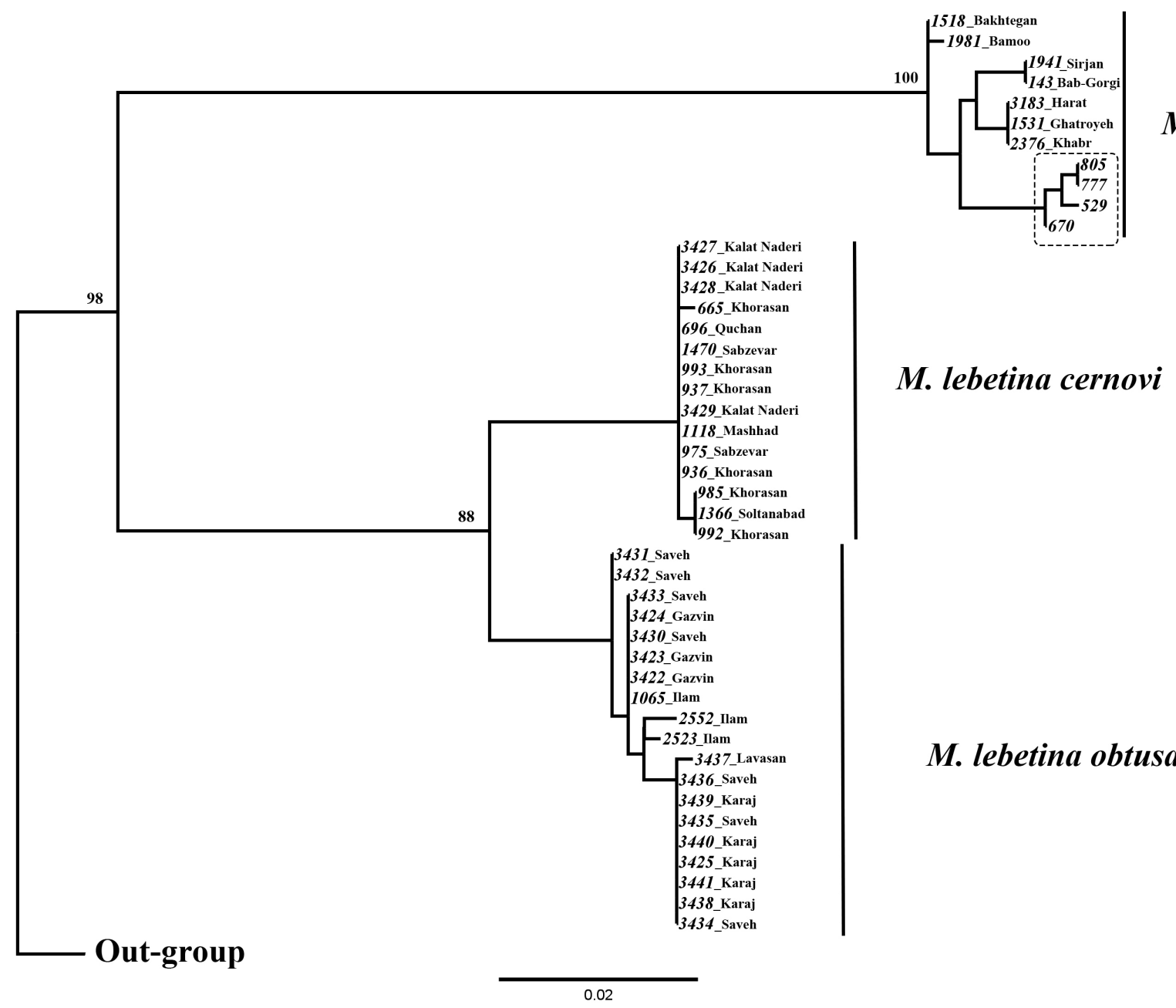

Figure 2. Phylogenetic tree resulting from a Maximum Likelihood (ML) reconstruction based on 604 base pairs of the Cytb sequence. The black box with dotted lines represents the individuals from central Zagros. Other samples originate from the study Oraie et al. (2018). Bootstrap support values from maximum likelihood analysis are indicated at the nodes. The tree was rooted using Montivipera raddei and Montivipera xanthina as out-groups.

the ultrafast bootstrap approximation algorithm. In order to investigate the haplotype diversity and structure, a median-joining haplotype network was constructed using the software PopART version 1.7 (Bandelt et al. 1999; http:// popart.otago.ac.nz) with the parameter epsilon set to 0 .

Estimates of evolutionary divergence ( $\mathrm{p}$-distance) over sequences indicate that samples from the central Zagros region do belong to the Macrovipera razii-branch. They are separated from other $M$. razii samples by more than $1.46 \%$. In my dataset $M$. razii has a higher within group variability than M. l. obtusa and M. l. cernovi. However, the sampling might not be representative for the last two mentioned taxa due to its restricted sampling coverage. According to the haplotype network, distinct mtDNA haplotypes in a well-structured geographic pattern were recovered (Fig. 1B). A phylogenetic tree showing position of the M. razii samples from central Zagros is in Fig. 2.

My data provide genetic evidence for the occurrence of Macrovipera razii more than $300 \mathrm{~km}$ north-west of the previous records in the south of Iran. This confirms a broader distribution range for this Iranian endemic species than was previously thought. The high genetic variability among populations of $M$. razii and well-structured geographic patterns of haplotypes are remarkable (Fig. 1B). It seems that after splitting of $M$. razii from M. lebetina around 10.5 Mya (Oraie et al. 2018), the former has differentiated and come to occupy diverse ecological niches over a broad distribution range in Iran (Oraie et al. 2018).

In conclusion, more fieldwork is needed to discover more populations and to define the exact distribution range of Macrovipera razii in Iran. Eventually, some national legislation and a well-designed monitoring program will be required to conserve this endemic species. The most serious threats for vipers including $M$. razii are the increase of agriculture, surface mining, urban development and collecting for the production of antivenin by the Razi Vaccine and Serum Research Institute. 


\section{Acknowledgments}

This work was supported by 97GRD1M31721 grant from the Shahrekord University. Thanks to Azar Khosravani for helping with the map and reviewing an earlier version of this manuscript. I appreciate Ali Reisi for his help in providing one specimen. I wish to thank the authorities from the Department of Environment of Chaharmahal and Bakhtiari Province for providing field-work facility. My special thanks go to Wolfgang Wüster for all his suggestions, and comments on the earlier drafts of this paper.

\section{References}

Bandelt HJ, Forster P, Röhl A (1999) Median-joining networks for inferring intraspecific phylogenies. Molecular Biology and Evolution 16: 37-48. https://doi.org/10.1093/oxfordjournals.molbev.a026036

Hall T (1999) BioEdit: a user-friendly biological sequence alignment editor and analysis program for Windows 95/98/NT. Nucleic Acids Symposium Series 41: 95-98.

Kalyaanamoorthy S, Minh BQ, Wong TKF, Von Haeseler A, Jermiin LS (2017) ModelFinder: Fast Model Selection for Accurate Phylogenetic Estimates. Nature Methods 14: 587-589. https://doi. org/10.1038/nmeth.4285

Khan MS (2004) Annotated Checklist of Amphibians and Reptiles of Pakistan. Asiatic Herpetological Research 10: 191-201.

Kumar S, Stecher G, Li M, Knyaz C, Tamura K (2018) MEGA X: Molecular Evolutionary Genetics Analysis across computing platforms. Molecular Biology and Evolution 35: 1547-1549. https://doi. org/10.1093/molbev/msy096

Lenk P, Kalyabina S, Wink M, Joger U (2001) Evolutionary relationships among the true vipers (Reptilia: Viperidae) inferred from mito- chondrial DNA sequences. Molecular Phylogenetics and Evolution 19: 94-104. https://doi.org/10.1006/mpev.2001.0912

McDiarmid RW, Campbell JA, Touré T (1999) Snake Species of the World: A Taxonomic and Geographic Reference. - vol. 1. Washington D.C., USA: Herpetologists' League.

Nguyen LT, Schmidt HA, Von Haeseler A, Minh BQ (2015) IQ-TREE: A fast and effective stochastic algorithm for estimating maximum likelihood phylogenies. Molecular Biology and Evolution 32: 268274. https://doi.org/10.1093/molbev/msu300

Oraie H, Rastegar-Pouyani E, Khosravani A, Moradi N, Akbari A, Sehhatisabet ME, Shafiei S, Stümpel N, Joger U (2018) Molecular and morphological analyses have revealed a new species of blunt-nosed viper of the genus Macrovipera in Iran. Salamandra 54 (4): 233-248.

Rastegar-Pouyani E, Rastegar-Pouyani N, Kazemi Noureini S, Joger U, Wink M (2010) Molecular phylogeny of the Eremias persica complex of the Iranian plateau (Reptilia: Lacertidae), based on mtDNA sequences. Zoological Journal of the Linnean Society 158: 641-660. https://doi.org/10.1111/j.1096-3642.2009.00553.x

Safaei-Mahroo B, Ghaffari H, Fahimi H, Broomand S, Yazdanian M, Najafi-Majd E, Hosseinian Yousefkani SS, Rezazadeh E, Hosseinzadeh MS, Nasrabadi R, Rajabizadeh M, Mashayekhi M, Motesharei A, Naderi A, Kazemi SM (2015) The herpetofauna of Iran: Checklist of taxonomy, distribution and conservation status. Asian Herpetological Research 6: 257-290.

Stümpel N (2012) Phylogenie und Phylogeographie eurasischer Viperinae unter besonderer Berücksichtigung der orientalischen Vipern der Gattungen Montivipera und Macrovipera. PhD Thesis, TU Carolo-Wilhelmina zu Braunschweig.

Stümpel N, Joger U (2009) Recent advances in phylogeny and taxonomy of near and Middle Eastern Vipers - an update. ZooKeys 31: 179-191. https://doi.org/10.3897/zookeys.31.261

Uetz P, Hošek J (2019) The Reptile Database. http://www.reptile-database.org [accessed December 2019] 